\title{
Associated depression in pseudophakic patients with intraocular lens with and without chromophore
}

This article was published in the following Dove Press journal:

Clinical Ophthalmology

31 March 2016

Number of times this article has been viewed

\author{
María Elena Mendoza- \\ Mendieta \\ Ana Aurora Lorenzo-Mejía \\ Association to Prevent Blindness in \\ Mexico (APEC), Hospital "Dr Luis \\ Sánchez Bulnes”, Mexico City, Mexico
}

Background: With aging, the crystalline lens turns yellowish, which increases the absorption of wavelengths in the blue electromagnetic spectrum, reducing their photoreception in the retina. Since these wavelengths are the main stimulus in the regulation of the circadian rhythm, progressive reduction in their transmission is associated with chronic sleep disturbances and depression in elderly patients. Cataract extraction improves circadian photoreception at any age. However, lenses that block blue waves have $27 \%$ to $38 \%$ less melatonin suppression than lenses that block only ultraviolet (UV) rays.

Purpose: To assess the depression symptoms in subjects who have had bilateral phacoemulsification and intraocular lens (IOL) implants, one group with yellow chromophore IOLs and the other group with transparent IOLs were compared.

Setting: Association to Prevent Blindness in Mexico (APEC), Hospital "Dr Luis Sánchez Bulnes".

Design: This was an observational, cross-sectional, and single-center study.

Materials and methods: Twenty-six subjects between 60 and 80 years of age, with a history of bilateral phacoemulsification and placement of the same type of IOL in both eyes from 4 to 12 months prior to the study, who attended the follow-up visits and agreed to participate in this study, and provided signed informed consent were included in the study. They were asked to answer the short version of the 15-item Geriatric Depression Scale.

Results: The average age of the study participants was $72.5 \pm 5.94$ years. The group without chromophore included $46.1 \%(n=12)$ of the patients and the group with chromophore included $53.9 \%(n=14)$ of the patients $(P=0.088)$.

Conclusion: In the group of patients with IOLs that block the passage of blue light, the depression rate was $21.4 \%$, a rate similar to that observed in the elderly population, whereas no patients in the group with transparent IOLs had depression.

Keywords: cataract, depression, intraocular lens, chromophore

\section{Introduction}

In 2002, it was discovered that $1 \%$ of ganglion retinal cells of rats are not visual but rather photoreceptive cells, which send information about environmental lighting through the retino-pituitary tract to the suprachiasmatic nucleus of anterior hypothalamus (biological clock), to synchronize geophysical cycles such as day and night, with the physiologic metabolism, through hormones such as cortisol and melatonin. ${ }^{1,2}$ These melanopsincontaining ganglion cells ${ }^{1}$ correspond to $0.3 \%$ in humans, ${ }^{3}$ and their peak spectral sensitivity is at $480 \mathrm{~nm},{ }^{1}$ closely matching the peak sensitivity for nonvisual responses 
of light, including melatonin suppression (446-477 nm) ${ }^{1}$ and circadian phase resetting $(460 \mathrm{~nm}){ }^{2,4}$ all included in the spectral sensitivity of blue light (440-500 nm). ${ }^{1,4}$

With aging, the crystalline lens gradually acquires a yellowish hue, which results in a progressive increase in absorbance within the blue range of the electromagnetic spectrum. ${ }^{2,4-7}$ In addition to senile miosis, ${ }^{2,5}$ this limits the blue light reaching the retina, thus reducing the effective retinal light exposure in older adults to one-tenth of that of younger people. ${ }^{7}$ Furthermore, it is reported that the lifestyles of elderly people may on average result in them having half of the total daily light exposure that a young adult would typically receive. ${ }^{8}$ Aging is furthermore associated with diminution in the number of photoreceptors ${ }^{2,4}$ and their sensitivity. ${ }^{4}$

All of these factors may lead to progressive loss of circadian photoreception, thus decreasing blue light melatonin suppression observed in older adults, ${ }^{2,7-9}$ and consequently its clinical manifestations such as sleep disturbances and depression $^{8,10}$ (diseases that can be treated with exposure to bright blue light sources). , $2,8,11,12^{2}$

On the other hand, circadian photoreception has been reported to improve after cataract surgery, ${ }^{2,13}$ decreasing insomnia and depression. ${ }^{10,13-16}$

As of 1986, filters began to be used in intraocular lenses (IOLs) to filter ultraviolet (UV) light, with the purpose of restoring the crystalline lens protection for intraocular tissue, ${ }^{2,4,5}$ but these filters soon extend into the range of short wavelengths of the visible blue light (attenuating optical radiation shorter than $500 \mathrm{~nm}$ ). Thus, the retina would be protected from "blue-light hazard", the phototoxic damage involved in the pathogenesis of age-related macular degeneration (ARMD), ${ }^{4,17,18}$ Although we lack clinical evidence to support the use of yellow IOLs, their use is still controversial due the potential side effects of blocking blue light, ${ }^{17}$ which is the part of the spectrum where rhodopsin, melanopsin, and melatonin suppression sensitivities are all maximal. ${ }^{4}$

The goal of this study was to assess the depression symptoms in subjects who have had bilateral phacoemulsification and IOL implants. For this purpose, one group with yellow chromophore IOLs and the other group with transparent IOLs were compared.

\section{Materials and methods}

This was an observational, cross-sectional, single-center, directly assigned, quantitative study, conducted over an 8-month period, and was approved by the Institutional Ethics and Research Committee of Association to Prevent Blindness in Mexico (APEC). The study included patients consulting at the Anterior Segment service, clinic number 3, at the APEC, Hospital "Dr Luis Sánchez Bulnes". The inclusion criteria were: subjects aged between 60 and 80 years, with a history of bilateral phacoemulsification and placement of the same type of IOL in both the eyes, who attended the follow-up visits and agreed to participate in this study, and signed the informed consent. They were asked to answer the short version of the 15-item Geriatric Depression Scale (GDS-15). ${ }^{19}$ All tests were performed, at least, 12 weeks postoperatively; it has been reported that normalization of chromatic and visual mechanisms occurs after 3-4 months. ${ }^{20,21}$

Subjects with a previous diagnosis of depression, single functional eye, history of eye surgery other than phacoemulsification, intraoperative complications such as capsular rupture or bleeding, or postoperative complications such as endophthalmitis, as well as subjects with previous eye diseases, such as uveitis, glaucoma, corneal opacities, ARMD, and proliferative diabetic retinopathy were excluded.

\section{Procedure}

The size of the sample was calculated for a $95 \%$ confidence level (CI), resulting in 8.10 subjects in each group.

Subjects with a history of bilateral cataract phacoemulsification and IOL placement in both the eyes who attended the follow-up visits were invited to participate in the study, and those who agreed and signed the informed consent were assigned to the IOL group with or without chromophore. Subsequently, the patients had a complete eye examination and answered the GDS- $15 .{ }^{22}$ GDS- 15 is a 15 -item questionnaire with a series of Yes/No questions and is used to measure depression in older adults. GDS- 15 has a mean sensitivity of 0.805 and a mean specificity of $0.750 .{ }^{19}$

Based on the scores of GDS-15, the following outcomes were defined:

- Normal range: from 0 to 4 points

- Suggestive of depression: 5 or more points.

\section{Statistical analysis}

A statistical analysis was performed. A descriptive analysis of the variables of interest through frequencies, percentages, mean, and standard deviation was made. Comparisons between the different variables included in the study groups with and without chromophore were made using Fisher's exact test for categorical variables (sex, type of IOL, and depression) and Student's $t$-test for continuous variables (age). A $P$-value $<0.05$ was considered significant for all these tests, and SPSS version 20.0 (IBM Corporation, Armonk, NY, USA) was used for the data analysis. 


\section{Results}

Twenty-six subjects, who met the inclusion criteria, were included in the study. Of them, $76.9 \%(n=20)$ were females and $23.1 \%(n=6)$ were males, with an average age of $72.5 \pm 5.94$ years. Participants were distributed as follows: $46.1 \%(n=12)$ in the group without chromophore and $53.9 \%$ $(\mathrm{n}=14)$ in the group with chromophore.

\section{Bivariate analysis}

In the group with chromophore, the average age was $71.8 \pm 5.04$ years, and in the group without chromophore was $73.1 \pm 6.74$ years, with no significant differences in age between the two groups $(P=0.585)$.

By sex, in the group with chromophore, $78.6 \%(\mathrm{n}=11)$ were women and $21.4 \%(n=3)$ were men, and in the group without chromophore, $75.0 \%(\mathrm{n}=9)$ were women and $23.0 \%$ $(\mathrm{n}=3)$ were men. No significant differences with regard to sex were found between the groups ( $P=0.829$ ).

In the group with chromophore, the IOL SN60WF was used in $100 \%(\mathrm{n}=14)$ of the patients, and in the group without chromophore, $66.7 \%(\mathrm{n}=8)$ of the patients used Asphina and $33.3 \%(n=4)$ used enVista.

Table 1 presents the number of patients per group according to their GDS-15 scores. As we can see in Figure 1, out of the 26 subjects studied, depression was observed in $21.4 \%$ $(n=3)$ of the subjects from the group with chromophore, while none of the subjects in the group without chromophore had depression. In consequence, subjects who scored within normal range in the GDS-15 in the group with IOL with chromophore were $78.6 \%(n=11)$, whereas the scores of all the patients in the group with IOL without chromophore were within normal range; however, the association between depression and chromophore group was not statistically significant $(P=0.088)$.

Table I Scores per patient, per group, in the GDS- 15 scale

\begin{tabular}{lll}
\hline $\begin{array}{l}\text { Score in the } \\
\text { GDS-15 scale }\end{array}$ & $\begin{array}{l}\text { Number of patients } \\
\text { in transparent } \\
\text { IOLs group }\end{array}$ & $\begin{array}{l}\text { Number of patients } \\
\text { in chromophore } \\
\text { IOLs group }\end{array}$ \\
\hline 0 & 6 & 5 \\
1 & 6 & 4 \\
2 & 0 & 1 \\
3 & 0 & 1 \\
4 & 0 & 0 \\
5 & 0 & 1 \\
6 & 0 & 0 \\
7 & 0 & 0 \\
8 & 0 & 2 \\
9 & 0 & 0 \\
$10-15$ & 0 & 0 \\
\hline
\end{tabular}

Abbreviations: GDS-15, the 15-item Geriatric Depression Scale; IOL, intraocular lens.

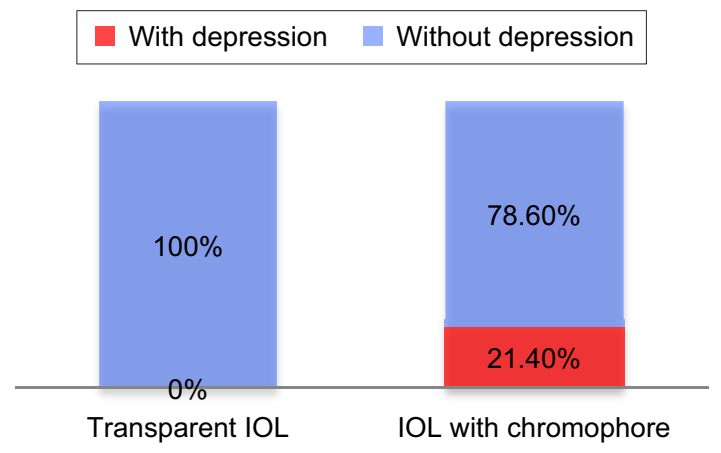

Figure I Depression per group. Abbreviation: IOL, intraocular lens.

\section{Discussion}

Age-related factors limit the blue light reaching the retina, ${ }^{7}$ producing disorganization in circadian rhythmicity, which is more common in older adults with depression..$^{2,4,12}$ Nonetheless, exposure to bright environmental light (sky $477 \mathrm{~nm}$ ) can restore melatonin levels. ${ }^{4,12}$ Circadian rhythmicity improves following cataract surgery, reducing symptoms of insomnia and depression. ${ }^{13-16}$

As of 1986, IOLs with filters began to be used, to restore natural crystalline protection against UV radiation, ${ }^{4}$ and later on IOLs with a yellow hue that mimics the brunescence of the 53-year crystalline len were designed, ${ }^{17}$ with the purpose of attenuating wavelengths between 300 and $500 \mathrm{~nm} .{ }^{17,23}$ The first IOL with this chromophore was the "AcrySof Natural ${ }^{\mathbb{R}}$ " (Alcon Laboratories, Fortworth, TX, USA). ${ }^{23}$

UV rays (200-400 nm) do not provide useful vision and are potentially dangerous, so we have natural protection against them, with the cornea preventing UV radiation shorter than $300 \mathrm{~nm}$ and the crystalline lens blocking most radiation between 300 and $400 \mathrm{~nm} .{ }^{4,18}$ So, it is logical to block wavelengths below $400 \mathrm{~nm}$ in IOLs.

In addition, the idea of blocking blue light is motivated by the hypothesis that blue light exposure is related to ARMD (known as "blue light hazard"). ${ }^{24}$ This is a popular hypothesis because, with aging, the risk of potential phototoxicity increases when the retinal pigment epithelium (RPE) accumulates lipofuscin, the primary mediators of "Ham-type" photic retinopathy or "UV-blue phototoxicity". However, A2E, the fluorophore constituent of lipofuscin, has its phototoxicity peak at $425 \mathrm{~nm}$, that is, in the violet part ${ }^{4,5}$ and not in the blue part of the electromagnetic spectrum.

Likewise, the physiopathology of the classic RPE phototoxicity damage involves an acute intensive exposure to blue light as experimental studies have described. ${ }^{5,18}$ However, epidemiological studies that correlate the association of a 
lifelong normal exposure with ARMD are inconclusive, $4,5,18,25$ mainly due to the difficulty of accurately estimating an individual's cumulative light exposure retrospectively, leading to studies with diverse results, in which some studies found no association, ${ }^{26-28}$ some a weak association, ${ }^{29,30}$ and one actually found that sunlight exposure was higher in the control group than in subjects with ARMD. ${ }^{31}$

A relationship between the incidence of ARMD and cataract extraction has been found in some studies, ${ }^{32}$ but with controversial results. ${ }^{4}$ In addition, the AREDS study found no correlation between cataract surgery and ARMD after specifically monitoring subjects for their ARMD status before cataract surgery. ${ }^{4}$

Despite the questionable role of cumulative normal exposure to blue light in the physiopathology of ARMD, the use of an IOL that brings potential protection to the retina has become popular. However, it is described that this IOL provides $20 \%$ less UV-blue phototoxicity protection than a 53-year old crystalline lens. ${ }^{4}$ Notwithstanding that most ARMD occurs in people over 60 years of age, 53-year old crystalline lenses do not prevent ARMD, ${ }^{4}$ and hence neither do IOLs with yellow chromophore. ${ }^{4}$

Moreover, sunglasses provide roughly 50\% more photoprotection than 20D blue-blocking IOLs, with the additional advantage of removability for optimal vision in dim environments. ${ }^{4}$

With regards to photoreception, blue light is responsible for 53\% of melanopsin suppression, and Mainster's study reported that blue-blocking IOLs provide 27\%-38\% less melatonin suppression than UV-only blocking IOLs. ${ }^{4}$ This coupled with the changes of aging, which lead to the progressive loss of photoreception, can be associated with a higher number of depression symptoms, among other manifestations of circadian rhythm dysfunction.

On analyzing the data provided in the results of this study, we can see that subjects with IOLs that block the passage of blue light trend to higher scores of depression symptoms, unlike the subjects with transparent IOLs. However, it is important to consider that the rate of depression reported in previous studies for a very similar population of elderly patients in ophthalmology clinics was $20 \%{ }^{33}$ and $21.6 \%,{ }^{14}$ which is a rate very similar to that observed in our chromophore group, at $21.4 \%$. A feasible explanation would be that placing the lens with a chromophore that mimics the brunescence of a 53-year old crystalline lens conforms to the incidence of depression in elderly patients.

It is worthwhile to consider that exposure to blue light has been considered a treatment for depression symptoms as well. This could explain why our group with a transparent IOL, which had an increased amount of blue light arriving to the retina, did not report depression symptoms.

The main limitation of this study is the lack of baseline assessment of depression in our patients; nevertheless, we note that baseline rates of depression in elderly patients visiting ophthalmologists has been studied earlier. ${ }^{14,33}$ We suggest that further studies with a larger sample size and baseline assessment of depression should be done, to determine whether a statistically significant difference exists between IOLs with and without chromophore. The search on PubMed and MEDLINE revealed that no similar studies have never been done earlier.

\section{Conclusion}

It is important to know the potential benefit that can be provided for patients by the use of IOLs without chromophore in the sense that cataract surgery is a unique opportunity to improve photoreception, in addition to improving vision, especially in elderly patients who often have comorbidities such as depression. Thus, in this age-group, IOLs without chromophore could be considered as an adjuvant for depression treatment.

\section{Acknowledgment}

The authors are thankful to Misael Gómez Urbina for his help with the bibliography research. Each patient paid for his or her surgery and intraocular lens.

\section{Disclosure}

The authors report no conflicts of interest in this work.

\section{References}

1. Brainard GC, Hanifin JP, Greeson JM, et al. Action spectrum for melatonin regulation in humans: evidence for a novel circadian photoreceptor. J Neurosci. 2001;21(16):6405-6412.

2. Turner PL, Mainster MA. Circadian photoreception: ageing and the eye's important role in systemic health. Br J Ophthalmol. 2008;92(11): 1439-1444.

3. Dacey DM, Liao HW, Peterson BB, et al. Melanopsin-expressing ganglion cells in primate retina signal colour and irradiance and project to the LGN. Nature. 2005;433(7027):749-754.

4. Mainster MA. Violet and blue light blocking intraocular lenses: photoprotection versus photoreception [perspective]. Br J Ophthalmol. 2006; 90(6):784-792.

5. Sparrow JR, Miller AS, Zhou J. Blue light-absorbing intraocular lens and retinal pigment epithelium protection in vitro. $J$ Cataract Refract Surg. 2004;30(4):873-878.

6. Barker FM, Brainard GC. The direct spectral transmittance of the excised human lens as function of age. Washington, DC: US Food and Drug Administration, 1991.

7. Charman WN. Age, lens transmittance, and the possible effects of light on melatonin suppression. Ophthalmic Physiol Opt. 2003;23(2): 181-187. 
8. Mishima K, Okawa M, Shimizu T, et al. Diminished melatonin secretion in the elderly caused by insufficient environmental illumination. J Clin Endocrinol Metab. 2001;86(1):129-134.

9. Herljevic M, Middleton B, Thapan K, et al. Light induced melatonin suppression: age related reduction in response to short wavelength light. Exp Gerontol. 2005;40(3):237-242.

10. Kessel L, Siganos G, Jorgensen T, et al. Sleep disturbances are related to decreased transmission of blue light to the retina caused by lens yellowing. Sleep. 2011;34(9):1215-1219.

11. Lieverse R, Van Someren EJ, Nielen MM, et al. Bright light treatment in elderly patients with nonseasonal major depressive disorder: a randomized placebo-controlled trial. Arch Gen Psychiatry. 2011;68(1): 61-70.

12. Terman M, Terman JS. Light therapy for seasonal and nonseasonal depression: efficacy, protocol, safety, and side effects. CNS Spectr. 2005;10(8):647-63; quiz 672.

13. Asplund R, Lindblad BE. Sleep and sleepiness 1 and 9 months after cataract surgery. Arch Gerontol Geriatr. 2004;38(1):69-75.

14. Ishii K, Kabata T, Oshika T. The impact of cataract surgery on cognitive impairment and depresive mental status in elderly patients $\mathrm{Am} \mathrm{J}$ Ophthalmol. 2008;146(3):404-409.

15. Wei X, She C, Chen D, et al. Blue-light-blocking intraocular lens implantation improves the sleep quality of cataract patients. $J$ Clin Sleep Med. 2013;9(8):741-745.

16. Ayaki M, Negishi K, Tsubota K. Rejuvenation effects of cataract surgery with UV blocking intra-ocular lens on circadian rhythm and gait speed. Rejuvenation Res. 2014;17(4):359-365.

17. Mainster MA, Sparrow JR. How much blue light should an IOL transmit? [perspective]. Br J Ophthalmol. 2003;87(12):1523-1529.

18. Sparrow JR, Nakanishi K, Parish CA. The lipofuscin fluorophore A2E mediates blue light-induced damage to retinal pigmented epithelial cells. Invest Ophthalmol Vis Sci. 2000;41(7):1981-1989.

19. Wancata J, Alexandrowicz R, Marquart B, Weiss M, Friedrich F. The criterion validity of the Geriatric Depression Scale: a systematic review. Acta Psychiatr Scand. 2006;114(6):398-410.

20. Delahunt PB, Webster MA, Werner JS. Long-term renormalization of chromatic mechanisms following cataract surgery. Vis Neurosci. 2004; 21(3):301-307.

21. Gray CS, Karimova G, Hildreth AJ, et al. Recovery of visual and functional disability following cataract surgery in older people: Sunderland Cataract Study. J Cataract Refract Surg. 2006;32(1):60-66.
22. Sheikh JI, Yesavage JA. Geriatric Depression Scale (GDS) recent evidence and development of a shorter version. In: Brink TL, editor. Clinical Gerontology: A Guide to Assessment and Intervention. New York: The Haworth Press; 1986: 165-173.

23. New Products. AcrySof Natural single-piece IOL earns FDA approval. Optom Vis Sci. 2003;80:616-617.

24. Glazer-Hockstein C, Dunaief JL. Could blue light-blocking lenses decrease the risk of age-related macular degeneration? Retina. 2006; 26(1):1-4

25. Cruickshanks KJ, Klein R, Klein BEK, et al. Sunlight and the 5-year incidence of early age-related maculopathy: the Beaver Dam Eye Study. Arch Ophthalmol. 2001;119(2):246-250.

26. Hirvela H, Luukinen H, Laara E, et al. Risk factors of age-related maculopathy in a population 70 years of age or older. Ophthalmology. 1996;103(6):871-877.

27. Delcourt C, Carriere I, Ponton-Sanchez A, et al. Light exposure and the risk of age-related macular degeneration: the Pathologies Oculaires Liees a’ l'Age (POLA) study. Arch Ophthalmol. 2001;119(10):1463-1468.

28. Clemons TE, Milton RC, Klein R, et al. Risk factors for the incidence of Advanced Age-Related Macular Degeneration in the Age-Related Eye Disease Study (AREDS) AREDS report no 19. Ophthalmology. 2005;112(4):533-539.

29. Taylor HR, West S, Muñoz B, et al. The long-term effects of visible light on the eye. Arch Ophthalmol. 1992;110(1):99-104.

30. Tomany SC, Cruickshanks KJ, Klein R, et al. Sunlight and the 10-year incidence of age-related maculopathy: the Beaver Dam Eye Study. Arch Ophthalmol. 2004;122(5):750-757.

31. Darzins P, Mitchell P, Heller RF. Sun exposure and age-related macular degeneration. An Australian case-control study. Ophthalmology. 1997;104(5):770-776.

32. Wang JJ, Klein R, Smith W, et al. Cataract surgery and the 5-year incidence of late-stage age-related maculopathy: pooled findings from the Beaver Dam and Blue Mountains Eye Studies. Ophthalmology. 2003;110(10):1960-1967.

33. Lee A, Beaver H, Jogerst G, Daly JM. Screening elderly patients in an outpatient ophthalmology clinic for dementia, depression, and functional impairment. Ophthalmology. 2003;110(4):651-657.
Clinical Ophthalmology

\section{Publish your work in this journal}

Clinical Ophthalmology is an international, peer-reviewed journal covering all subspecialties within ophthalmology. Key topics include: Optometry; Visual science; Pharmacology and drug therapy in eye diseases; Basic Sciences; Primary and Secondary eye care; Patient Safety and Quality of Care Improvements. This journal is indexed on

\section{Dovepress}

PubMed Central and CAS, and is the official journal of The Society of Clinical Ophthalmology (SCO). The manuscript management system is completely online and includes a very quick and fair peer-review system, which is all easy to use. Visit http://www.dovepress.com/ testimonials.php to read real quotes from published authors. 